\title{
The Hudson-Stahli Line III: Observations on Morphology, a Critical Review of Aetiology and a Unified Theory for the Formation of Iron Lines of the Corneal Epithelium
}

\author{
GEOFFREY E. ROSE and MICHAEL J. LAVIN \\ London
}

\begin{abstract}
Summary
Observations as to the morphology, position and orientation of the Hudson-Stahli line are presented, based on the slit-lamp biomicroscopic examination of the eyes of six hundred and forty-four subjects.

The origin of the pigments in the Hudson-Stahli zone and other corneal epithelial lines is reviewed, the evidence for either tear film dynamics or epithelial dynamics influencing the typical configuration is discussed and a unified theory for the formation of corneal iron lines is presented.
\end{abstract}

The Hudson-Stahli line, described independently by Hudson ${ }^{1}$ and Stahli, ${ }^{2}$ is still relatively poorly documented and explanations for its occurrence are often illogical or inconsistent. This paper contains a critical review of current theories, observations made during a study of normal eyes and a unified theory to attempt explanation of the characteristic configurations of the many corneal epithelial iron lines.

\section{Material and Methods}

Hudson-Stahli lines were documented during slitlamp biomicroscopic examination of the eyes of 644 subjects (94 of whom wore contact lenses) attending an ophthalmic accident and emergency department. None of the subjects had corneal disease and none were using long-term ocular medication.

The examination methods and some of the results from these groups of patients have been presented in previous reports; $;^{3,4}$ the present paper documents observations about the form and position of the line in normal eyes and after contact lens wear.

\section{Results}

(A) Morphology of Hudson-Stahli line

The earliest clinical evidence of HudsonStahli line is a faint zone of pigment about 1 to 2 millimetres in (vertical) width, lying horizontally across the cornea; this configuration is the commonest variant in all age groups ${ }^{3}$ and seems to broaden (to 3-5 mm) during contact lens wear. ${ }^{4}$ Occasionally a faint line, or reticulum of interlacing lines, is superimposed on the broad zone of pigmentation. Because this diffuse pigmentation is the commonest form, we consider it more appropriate to name it the Hudson-Stahli zone.

As the pigment increases, so the zone tends to assume the more clearly defined, narrower line as described in early works,,${ }^{1,2}$ although generally there is a broad background of faint pigmentation. This background pigmentation is implied by Gass ${ }^{5}$ when he states that the 'superior and inferior borders [of HudsonStahli lines] blend imperceptibly into normal cornea'.

In the present study, many lines of higher 
density and length showed multiple ramifications, variable density and variable width, the commonly branching ends often merging into areas of faint pigmentation.

\section{(B) Position of Hudson-Stahli Zone}

Irrespective of density, length or morphology, the zone always lies very close to the junction of the upper two-thirds and lower one-third of the normal cornea. In contrast, contact lens wear tends to broaden the zone superiorly and in two rare cases displaced the pigment wholly into the upper half of the corneal epithelium.

The position of pigment along this almost constant horizontal locus is variable. Short, faint lines typically straddle the vertical midline of the cornea, the more defined lines tend to have a nasal bias and the longest of lines extend from close to the temporal limbus towards the nasal limbus. These positions along the horizontal locus do not change with contact lens wear.

\section{(C) Orientation and Shape of Hudson-Stahli Zone}

The commonly occurring faint zone is generally horizontal. Although often ramifying, the overall orientation of more clearly defined Hudson-Stahli lines is generally horizontal within the temporal half of the cornea and upward-turning as it passes nasally; the resultant line and zone, therefore, tends typically to be convex inferiorly and to be slightly higher at the medial end.

\section{(D) Continuity with other Corneal Epithelial Pigmentations}

The Hudson-Stahli line can fuse with a Stocker line at the head of a pterygium, ${ }^{5}$ this phenomenon having been observed with pterygia and prominent pinguecula in the present study. In many eyes with scars of Bowman's zone (as a result of previous injury) we have observed an intense pigmentation over the scar and, in some cases, the Hudson-Stahli line deviating into these areas. A similar phenomenon has been reported by other authors. ${ }^{5,6}$

The contribution of melanin to the formation of Hudson-Stahli line has been proposed previously, ${ }^{7}$ although Gass suggests that melanin lines of the cornea are distinguishable from the iron pigmentation of the HudsonStahli line. ${ }^{5}$ We have noted that the central extensions of limbal melanosis, whilst distinguishable from Hudson-Stahli lines in peripheral areas, merge imperceptibly with the Hudson-Stahli zone in many cases; indeed, we propose that a contribution of melanin from limbal melanocytes might explain the clinical prominence of the lines in brown eyes as compared to blue eyes, ${ }^{3}$ limbal melanosis occurring almost exclusively in brown eyes.

\section{Discussion}

In this section we review the nature and origins of epithelial pigments and theories for the formation of the typical configurations. We propose a unified theory of epithelial pigment line formation and discuss it with reference to abnormal corneas.

\section{(A) Origins of pigments in Hudson-Stahli zone}

The composition of the Hudson-Stahli line is controversial and has been variously attributed to 'alkali haematin," haemosiderin, ${ }^{8}$ melanin ${ }^{7}$ or ferritin'. ${ }^{9}$ Electron microscopy of corneal pigment lines shows ferritin to be the predominant pigment, this occurring mainly in the basal layers, both within and between the cells. ${ }^{9,10}$

The corneal iron has been considered to come from tears, plasma, perilimbal tissues and tear film blood, aqueous humour or the breakdown of intracellular enzymes. ${ }^{5}$ Iron concentrations are greatest in the corneal epithelium ${ }^{11}$ and diffusion would not be expected to occur from the lower concentrations in the tears, stroma or aqueous. ${ }^{11.12}$ The occurrence of iron throughout the basal epithelium, ${ }^{5,9,10,13}$ the high iron-binding affinity of tear lactoferrin,${ }^{14}$ the poor diffusion of ionic iron across corneal epithelium ${ }^{15}$ and the presence of a Hudson-Stahli line in the absence of tear secretion, ${ }^{16}$ all argue strongly against a tear film origin. Whilst erythrocytes have been reported in tear film, ${ }^{16}$ these probably arise from trauma during tear collection. The Hudson-Stahli zone represents a concentration of the widely-scattered pigments that occur in the basal epithelium throughout the corneal surface, ${ }^{5.9}$ implying them to be a normal component or selectively accrued by this layer; 
there do not appear to be any studies of the iron-binding properties of different layers of the epithelium. Other sources, such as the perilimbal tissues that supply the centrally migrating basal epithelial cells, appear the most likely source of the iron.

\section{(B) Theories for the configuration of the Hudson-Stahli line}

There are two principal hypotheses as to why the zone assumes such a characteristic position and configuration-namely, that it is a property of tear film dynamics or that it is a result of epithelial microtrauma. In an effort to resolve this controversy, the theoretical requirements for each of these will be examined in the light of clinical observations.

\section{(i) Tear line and tear 'pooling' hypotheses}

These hypotheses suggest that tear film iron is sequestered within basal epithelium, $, 5,13,17$ the typical situation of the line being a result of the tear line at the margin of the lower $\operatorname{lid}^{13}$ or a result of changing ionic concentrations due to tear film evaporation. ${ }^{5.16}$ Other iron lines, such as those of Fleischer, ${ }^{18}$ Ferry ${ }^{19}$ or Stocker ${ }^{20}$ are proposed to develop from a 'pooling' of tears in concavities on the corneal surface. ${ }^{13}$

The concept of a tear 'pool'-that is, increased bulk at the tear line or in surface irregularitiesdoes not satisfactorily explain the formation of pigment lines: If the tear film was a static, unreplaced solution bathing the cornea, then a larger bulk of tears would maintain a diffusion gradient for a longer time and thereby increase the quantity of diffused iron in the area of the tear 'pool'. In life this does not exist and the anterior surface of the cornea can be regarded as being bathed in a solution with an almost constant concentration of iron, irrespective of the thickness or position of the tear film on the cornea. Prolonged exposure sufficient to cause tear film concentration occurs clinically only in severe lagophthalmos and not in normal subjects; lesser degrees of exposure, such as that of nocturnal lagophthalmos, are too infrequent to explain the Hudson-Stahli zone and also too well compensated by Bell's phenomenon and other nocturnal eye movements.

Other clinical observations do not fit with the tear 'line' hypotheses: As already discussed, passive diffusion of iron from the tear film cannot explain the corneal epithelial iron lines; if an as yet unidentified active transport mechanism existed, this would result in the uniform distribution of iron across the entire epithelium, and not in the typical iron lines. If the Hudson-Stahli line is related to the tear line at the inferior lid margin, then a similar line should be observed at the superior tear linethis not being so-and the Hudson-Stahli line should not be observed in sicca syndromes, although Norn reports just such a case. ${ }^{16}$ On the basis of a tear film phenomenon it is hard to explain the branching of lines and the pigmentation of smooth scars of Bowman's zone (these scars not interfering with tear flow patterns). Iron pigments have also been shown in infant corneas. ${ }^{5}$

\section{(ii) Epithelial microtrauma hypotheses}

The situation of the Hudson-Stahli zone at the interpalpebral fissure has long suggested that lid movement or its effect on epithelial integrity might influence line formation. ${ }^{15.13}$ Attrition of the epithelium by the lid margins or in areas of surface elevation, might predispose to the sequestration of tear film iron at these sites. ${ }^{5}$ However, whilst such an attrition would explain the position of the zone at the interpalpebral fissue, it does not account for other iron lines that typically occur in the concavities surrounding areas of elevation. Two observations favour the movement of epithelium as influencing the disposition of pigments in corneal epithelium: The pigment lines being situated either at areas of high epithelial turnover (namely, the Hudson-Stahli zone and over scars of Bowman's zone) or alongside such areas (by filtering blebs, pterygia, keratoconus or corneal nodules ${ }^{6,18,19,20}$ ) suggests that the distribution of iron is related to epithelial movements in these areas. Further evidence is provided by the striking similarity between the Hudson-Stahli line and the migration-related corneal epithelial vorticellate patterns of Fabry's disease, chloroquine, amiodarone and Atebrin;21,22,23 indeed we have observed the almost exact superimposition of well-defined branching Hudson-Stahli lines and amiodarone keratopathy lines in a patient with both conditions. The central extensions of limbal melanosis onto the corneaagain, related to patterns of epithelial migrationoften merge with the lines of Hudson-Stahli zone. ${ }^{37.8}$ Although occasional reports have implied that corneal epithelial pigment lines may be related to epithelial migration, no details or explanations have been provided. ${ }^{24} .25$ We provide a unified theory to explain these various epithelial lines.

\section{A Unified Theory for the Aetiology of Corneal Pigment Lines}

At any point in the corneal surface, the concentration of pigment is related to the quantity of the intracellular and extracellular pigments. Factors likely to increase pigment 
in cells are the age of the cell and mitotic rate; increased mitosis might be expected to deplete the pigments in basal layers because of cytoplasmic division between parent and daughter cell. The extracellular pigment is probably lost into superfical layers of epithelium (especially in areas of attrition) and might originate from cell divisions (being mixed with cell membrane debris ${ }^{9}$ ); this pigment should increase with cell age as neighbouring cells undergo more divisions.

Different epithelial cells migrate in different directions: The basal epithelia migrate centrally from their origin at the limbus, ${ }^{26-31}$ these cells proliferating ${ }^{32}$ to produce superficial epithelial cells that migrate towards the free surface of the epithelium (the ' $\mathrm{X}, \mathrm{Y}, \mathrm{Z}$ ' hypothesis ${ }^{27}$ ). In any small area of epithelium, basal cells (along with pigments from the limbus) migrate across the area, the rate being limited initially by the rate of influx of cells from the periphery. The rate within the area is then modified by the number of basal cell mitoses needed, a high demand for superficial epithelium slowing or halting the migration of basal cells. Those basal cells reaching the central 'edge' of the area under consideration would continue their central migration until stopped by cells migrating in the opposite direction (the migration 'null line').

In the normal cornea, attrition is greatest at the interpalpebral fissure in the lower twothirds of the cornea. In this area, the migration of basal cells would be slower, causing the migration 'null line' to occur in the lower part of the cornea; this 'null line' is almost certainly where the Hudson-Stahli zone and vorticellate keratopathies are localised. Not only does the 'null line' have the oldest basal cells, these having the most extracellular pigment, but also it receives pigment from two directions, rather than one, and would be expected to have a more pronounced pigmentation. Such a pattern of basal cell migration should produce the Hudson-Stahli zone as seen histologically and clinically-pigment present throughout the cornea ${ }^{5.9 .13}$ and increasing towards the zone, ${ }^{5,13}$ with or without a welldefined line at the 'null line'.

Disturbance of Bowman's zone is known to predispose to recurrent erosion of the corneal epithelium $^{33}$ and flat scars of Bowman's zone almost certainly slow basal epithelial migration. A scar in superior cornea would slow the downward migration of basal cells from the superior limbus, this shifting the 'null line' (and its pigmentation) upwards towards the scar; if slowed sufficiently, the epithelial "null line' would coincide with the scar and the pigment would appear to deviate into the area of the scar-a well recognised clinical sign.

Attrition of superficial epithelium, by slowing the migration of basal cells across the eroded area, would caused a shift of the 'null line'. towards the areas of attrition. However, although the 'null line' might be displaced even as far as the area of attrition, any tendency for this to become the maximally pigmented area is negated by the higher rate of epithelial (and hence pigment) loss into superficial layers. Because of this attenuation of pigmentation by loss, the area of maximal pigmentation would be expected alongside the area of attrition, as seen clinically with the lines of Fleischer, ${ }^{18}$ Stocker $^{20}$ and Ferry ${ }^{19}$ these lines always occurring centrally to their causative elevations.

Similarly, the more complex scars of Bowman's zone after radial keratotomy,${ }^{17}$ corneal transplantion, ${ }^{34}$ or refractive keratoplasty ${ }^{10}$ alter the migration patterns of basal epithelium and change the distribution of pigments. Contact lens wear, by increasing the abrasion of the corneal epithelium (particularly superiorly), would be expected to shift the 'null line' of migration upwards with respect to normal corneas, such change having been seen in a series of contact lens wearers. ${ }^{4}$

A further understanding of the aetiology of the Hudson-Stahli zone and other iron lines of the cornea would be provided by examination of the eyes of subjects with lid abnormalities (lagophthalmos or ptosis) or with sicca syndromes and also a study of the reformation of lines after epithelial debridement, after corneal transplantation or after discontinuing the wear of contact lenses. In subjects with ptosis, the reduced lid movements and epithelial attrition would, on the basis of the proposed unified hypothesis, be expected to shift their Hudson-Stahli zone superiorly-a conjecture yet to be examined. 


\section{References}

${ }^{1}$ Hudson AC: A note on certain peculiar pigmentary markings in the cornea. Roy Lond Ophthal Hosp Rep 1911, 18: 198-202.

2 Stahli J: Ueber den Fleischerschen Ring beim Keratokonus und eine neue typische Epithelpigmentation der normalen Kornea. Klin Monatsbl Augenheilk 1918, 60: 721-41.

${ }^{3}$ Rose GE and Lavin MJ: The Hudson-Stahli line I: An Epidemiological Study. Eye 1987 (In Press).

${ }^{4}$ Rose GE and Lavin MJ: The Hudson-Stahli line II: A Comparison of Properties in Eyes with and without Long-term Contact Lens Wear. Eye 1987 (In Press).

${ }^{5}$ Gass JD: The iron lines of the superficial cornea. Hudson-Stahli line, Stocker's line and Fleischer's ring. Arch Ophthal. 1964, 71: 348-68.

${ }^{6}$ Reinach NW and Baum J: A corneal pigmented line associated with Salzmann's nodular degeneration. Am J Ophthalmol 1981, 91: 677-8.

${ }^{7}$ Friedenwald JS, Wilder HC, Maumenee AE, Saunders TE, Keyes JEL, Hogan MJ, Owens WC, Owens EL: Ophthalmic Pathology: an atlas and textbook. WB Saunders, Philadelphia, 1952, pp 220, 226.

${ }^{8}$ Duke Elder SE: System of Ophthalmology. Kimptons, London. 1965, Vol XIV part 2, pp 1040.

${ }^{9}$ Iwamoto T and DeVoe AG: Electron microscopical study of the Fleischer ring. Arch Ophthalmol 1976, 94: 1979-84.

${ }^{10}$ Koenig SB, McDonald MB, Yamaguchi T, Friedlander M. Ishii Y: Corneal iron lines after refractive keratoplasty. Arch Ophthalmol 1983, 101: 1862-5.

11 Tauber FW and Krause AC: The role of iron, copper, zinc, and manganese in the metabolism of the ocular tissues with special reference to the lens. Am J Ophthalmol 1943, 26: 260-6.

12 Liotet S: Étude du fer et du cuivre et de leurs proteins de transport dans les larmes humaines. Ann Oculist (Paris) 1969, 202: 629-35.

${ }^{13}$ Barraquer-Somers E, Chan CC, Green WR: Corneal epithelial iron deposition. Ophthalmology 1983, 90: 729-34

${ }^{14}$ Aisen PH and Liebman A: Lactoferrin and transferrin: a comparative study. Biochim Biophys Acta 1972, 257: 314-19.

15 Maurice DM: The permeability of the cornea Ophthal Lit 1953, 7: 3-26.

${ }^{16}$ Norn MS: Hudson-Stahli's line of cornea. Il Aetiological studies. Acta Ophthalmol 1968, 46: $119-28$.

17 Steinberg EB, Wilson LA, Waring GO, Lynn MJ,
Coles WH: Stellate iron lines in the corneal epithelium after radial keratotomy. $A m \quad J$ ophthalmol 1984, 98: 416-21.

${ }^{18}$ Fleischer B: Ueber Keratokonus und Eigenartige Pigmenbildung in der Kornea. Munchen Med Wschr 1906, 93: 625-6.

${ }^{19}$ Ferry AP: A 'new' iron line of the superficial cornea. Occurrence in patients with filtering blebs. Arch Ophthalmol 1968, 79: 142-5.

21 Stocker F: Eine Pigmentierte Hornhautlinie beim Pterygium. Klin Monatsbl Augenheilk 1939, 102: 384-90.

${ }^{21}$ D’Amico DJ, Kenyon KR. Ruskin JN: Amiodarone keratopathy. Drug induced lipid storage disease. Arch Ophthalmol 1981, 99: 297-361.

22 Spencer WH: Ophthalmic Pathology. WB Saunders, Philadelphia, 1985, 3 ed, pp 370, 372.

${ }_{23}^{23}$ Mann I: 'Blue haloes' in atebrin workers. $\mathrm{Br} J$ Ophthalmol 1947. 31: 40-6.

${ }^{24}$ Davangar $M$ and Evensen A: Role of the pericorneal papillary structure in renewal of corneal epithelium. Nature 1971, 229: 560-1.

${ }_{25}$ Moncrieff BK: An atypical pigment line of the cornea: A biomicroscopic and histologic study. Arch Ophthalmol 1932, 8: 847-51.

${ }^{26}$ Shapiro MS, Friend J, Thoft RA: Corneal re-epithelialisation from the conjunctiva. Invest Ophthalmol Vis Sci 1981, 21: 134-42.

27 Thoft RA and Friend J: The X,Y,Z hypothesis of corneal epithelila maintenance. Invest Ophthalmol Vis Sci 1983, 24: 1442-3.

${ }^{28}$ Gipson IK and Anderson RA: Effect of lectins on migration of the corneal epithelium. Invest Ophthalmol Vis Sci 1980, 19: 341-9.

${ }^{29}$ Buck RC: Measurement of centripetal migration of normal corneal epithelial cells in the mouse. Invest Ophthal Vis Sci 1985, 26: 1296-9.

${ }^{30}$ Buck RC: Ultrastructural characteristics associated with the anchoring of corneal epithelium in several classes of vertebrates. J Anat 1983, 137: 743-56.

${ }^{31}$ Kaye DB: Epithelial response in penetrating keratoplasty. Am J Ophthalmol 1980, 89: 381-7.

32 Schermer A, Galvin S. Sun T-T: Differentiationrelated expression of a major $64 \mathrm{~K}$ corneal keratin in vivo and in culture suggests limbal location of corneal epithelial stem cells. J Cell Biol 1986. 103: 49-62.

${ }^{33}$ Williams R and Buckley RJ: Pathogenesis and treatment of recurrent erosion. BrJ Ophthalmol 1985. 69: 429-7.

${ }^{34}$ Mannis MJ: Iron deposition in the corneal graft. Another corneal iron line. Arch Ophthalmol 1983, 101: 1858-61. 